\title{
Motivating Your Staff to Provide Outstanding Service
}

\author{
Michael C. Sturman and Robert Ford
}

Your service environment is superb, your operations are efficient, your concept reflects a clear idea of the customers' demands, and your back-of-the-house delivery system is flawless-so far, so good. Now it's up to that front-line employee you've worked so hard to hire and train to deliver the service you've promised, because the guest contact employee usually is the key to having a satisfied guest. Say that there's a problem at the front desk, and a guest's room is out of order or not acceptable. This is the moment of truth. If the front-desk associate is rushed or dealing with a heavy check-in, he or she may not be able to respond to the guest's problem or may be too casual about the problem. Suddenly, all your careful planning is for naught. If the guest feels shabbily treated, the guest will also be angry at your hotel, since the employee represents the hotel. It makes no difference whether the guest's reaction is fair or appropriate. Since quality and value are defined by the guest, the employee who provides the guest experience must be not only well trained but highly motivated to meet the guest's quality and value expectations and to do so consistently. Your role as a manager responsible for providing an exceptional service experience, and specifically for preparing your staff to deliver such service, is vital. In this chapter, we argue that motivating your employees is as critical for excellent service as is training them.

\section{Motivating Employees}

Let's look at the way in which a motivated front-desk clerk handled an actual room reservation problem. A family was checking in at the Hyatt Grand Cypress on a busy night. The hotel was full, the family's reservation had not been properly handled, and the husband, wife, and three tired children were upset. The front-desk employee assessed the situation and acted promptly. Rather than force the family to hang out in the lobby until things were straightened out, she took some quarters out of the petty cash drawer and gave them to the kids to go and play the video games and gave the parents chits for a drink in the lobby bar. That gave her the necessary time to find a manager to straighten out the problem. The parents were happy, the kids were happy, and the front-desk person had defused a tense situation. 
In contrast, you may have heard about the experience of Tom Farmer and Shane Atchison, whose situation eventually went viral on the Internet. They had a confirmed reservation at a hotel, and the room had supposedly been guaranteed by credit card for late arrival. Yet when they arrived a 2:00 AM, they were refused rooms. Tom and Shane publicized their service experience by posting an open complaint to the hotel, called "Yours Is a Very Bad Hotel." ${ }^{1}$ They report that "Mike the Night Clerk" was "deeply unapologetic," "had done nothing about finding [them] accommodation elsewhere," and when they suggested that he should have lined up other rooms in advance, Mike the Night Clerk "bristled!" Explaining why the customers were wrong to be upset that their "guaranteed" room was not saved for them, Mike told them, "I have nothing to apologize to you for." After the posting, representatives of the hotel did apologize and reportedly improved their training and overbooking policies, but the damage was done. A Google search in December 2010 on the phrase "Yours Is a Very Bad Hotel" yielded 15,200 results!

Both of the above situations had the same essential cause: a failed reservation. The key here is that the employees' actions brought markedly different results. The Hyatt's desk clerk was motivated to keep the customers satisfied despite a problem that was not of her making, whereas Mike the Night Clerk apparently could not have cared less. As you read this chapter, consider how your employees might respond to a common situation like this one. Your challenge is to discover what motivates your employees not only to do their jobs efficiently and competently but also to go the extra mile for your guests.

In this chapter, we discuss various ideas that will help you motivate your staff. We have divided these ideas into financial approaches and nonfinancial methods-all aimed at helping you motivate your staff to offer the best possible guest experience even when things don't go right. We have all seen that it's impossible to predefine policy and procedures for all guest situations. Something unexpected always comes up. Thus, employees should know that they are encouraged, expected, and trusted to handle all the many and varied situations that come up in the guest service areas for which they are responsible. If they were properly selected and trained in the first place, management must make it possible for them do their jobs with responsibility, skill, enthusiasm, and fun. The purpose of this chapter is to consider the many ways you can accomplish this.

The motivation, the drive, or compelling force that energizes people to do what they do comes from either inside the employees (intrinsic motivation) or from the environment (extrinsic motivation). The best organizations create an environment and policies that enhance both forms of motivation. It's critical to note right at the start that money-important though it may be-is not your employees' only 
motivating factor. You can motivate employees not only by offering financial rewards, but also providing nonfinancial rewards, or even changing the nature of the job itself. Decades of economic and psychological research have shown that motivation is influenced by numerous factors, including the organization's environment, organizational culture, individual characteristics, comparison across individuals, and the structure and form of existing incentives. Unfortunately, it is impossible for us to offer you simplistic prescriptions on how to increase your employees' motivation, but you do have a wide variety of tools at your disposal to create and sustain an environment where employees want to go the extra mile.

\section{Financial Rewards}

Let's start with the most common motivator-money. Your employees receive direct compensation (wages or salary). You probably also offer indirect compensation, which puts money in your employees' pockets by giving them services and benefits, such as deferred compensation and health insurance. You may also have at-risk pay, where rewards (if they are given at all) depend on various factors, like individual, team, or organizational performance.

Psychological research is filled with different theories and studies of motivation, many of which are applicable to understanding financial incentives. We won't describe all of these ideas, but let's look at four factors that researchers have identified for why money motivates your workers-or fails to do so. Those factors are individual needs, the power of reinforcement, the expectancy of getting rewards, and the fairness of the rewards.

\section{The Power of Individuals' Needs}

To meet employees' living needs, the most obvious inducement is money. Most of your employees are working because they need to earn a living - even if they work in your hotel or restaurant for other, nonmonetary reasons. Motivational speakers like to talk about higher-order needs like social, recognition, or achievement needs, but none of those count if a person is concerned about how they are going to get their next meal, pay their rent, or buy warm clothes in the winter.

You must pay your employees enough to meet their survival needs before they can effectively use incentives or rewards to help satisfy their other needs. ${ }^{2}$ While you may not be in the financial position to suddenly increase wages or offer health benefits, you are not powerless either. There are other valued incentives to help them, such as scheduling enough hours, working around child or elder care responsibilities, and helping employees find affordable health care for their families. Listening to 
employees' needs and preferences (as described in Chapter 4) often reveals simple available solutions. Such an approach can go a long way to satisfy employees' needs.

\section{The Power of Positive Reinforcement}

The idea of positive reinforcement is a well-accepted psychological principle. If you reward desired behavior and don't reward undesired behavior, you will get more of the desired behaviors and fewer of the undesired ones. While the idea seems straightforward, successfully using positive reinforcement in the workplace is challenging. Too often, time pressures compel you to focus on the annoying "squeaky wheel" rather than the quietly effective employee. Rewarding the wrong behavior is as big a mistake as not rewarding the right behavior.

Here's an example of how improper reinforcement unintentionally changed the nature of a greeter position for one restaurant. The manager initially told the newly hired employee explicitly that his primary responsibility was to greet and welcome guests. As time went on, however, to keep the employee busy when guests were not entering the restaurant, the manager added responsibilities to the position-such as checking periodically to make sure there were enough trays or making sure that the butter dish was always full. The greeter quickly realized that the manager never complimented him for properly greeting the guests, nor did the manager ever say anything to him when he missed a guest because he was too busy with his other duties. But if he ever let the buffet line run out of trays or butter, he was strongly reprimanded. Therefore, by reinforcing certain employee actions, the manager had redefined the job. The manager made her real priorities clear, the employee adjusted his actions accordingly, and the restaurant no longer reliably offered a greeting to guests.

\section{The Power of Goals and Expectancy}

Another key way to motivate employees is by setting challenging yet still attainable goals. Research on goal setting has repeatedly shown that setting specific and challenging goals leads to higher levels of task performance than do easy or vague goals, or telling people to "do their best." If you couple challenging goals with compensation, you have a powerful force to motivate exceptional employee performance. Of course, as shown by the case of the buffet greeter, rewarding the wrong behavior can sabotage motivation. Goals could be too easy or too challenging, may induce unethical behavior or inappropriate risk taking, or may motivate behaviors leading to rewarded tasks at the expense of other, equally important, but unrewarded tasks. ${ }^{3}$

Harrah's casino uses a combination of goal setting and future rewards to motivate both individual and team behavior. Sales staff employed in Las Vegas are rewarded for making sales goals set 
for the individual person, the hotel, and Harrah's group of hotels in the Las Vegas area. Managers work with the teams to make sure the goals are challenging but attainable. Successful performance is rewarded with both bonus checks and merchandise that the employees can pick out (such as Weber grills and vacation packages). These goals extend beyond simply sales numbers. All employees can achieve bonuses based on a number of critical metrics, including customer service scores. Setting these goals, rewarding them, and using goals that are clearly connected to the company's strategy of excellent customer service allows Harrah's to get highly motivated staff and exceptional performance.

\section{The Power of Equity}

Reinforcement, goal setting, and expectancy assume that people make decisions based purely on their own circumstances, but people are social creatures. We see what others do and get, compare ourselves against others, and decide what is fair or unfair, just or unjust. If someone thinks that other employees were given more rewards for similar efforts, this will create feelings of injustice. Feelings of being underpaid have been linked to lower motivation, greater absenteeism, higher turnover, and even increased theft. We hasten to add that employees' feelings of lack of equity involve being comparatively underpaid-few people admit that they are overpaid and feel bad about it.

Individuals will compare against others, both inside and outside of the company. Your employees will compare themselves to their coworkers, to subordinates, and even to the boss, all the time evaluating whether pay differences are (in their eyes) just or unjust. Your employees will also try to figure out what the "market" is paying for their job, talk to friends who are doing similar jobs at other organizations, look at other jobs they might be able to take, or even consider other careers they might pursue. Making this even more confusing, people will often form judgments of fairness based on their perceptions of their own worth or perceptions of others' pay-neither of which may be accurate. ${ }^{4}$ Most know how important fairness is in compensation systems. Indeed, for the process of determining Fortunes "100 Best Companies to Work For" list, compensation fairness is a key criterion.

\section{Types of Performance-Based Financial Rewards}

With those principles in mind, let's look at possible performance-based financial rewards. Your challenge is to discover what employees consider equitable and appropriate and then provide rewards that fit those criteria, while also being fiscally prudent. To make rewarding good performance even harder, employees have changing expectations, moods, and valuations of the employment relationship. 
Your first step is to identify the rewards that employees desire. Most employees begin new jobs with energy and enthusiasm. They want to do well. So your motivation program should build on this good start by offering encouragement and help. By giving your employees desired rewards for performance, you can keep people energized, enthusiastic, and working hard. Fortunately, you can choose among many different sorts of financial rewards to do this. We've summarized these rewards in Table 11.1.

- Let's look at some of these financial incentives, many of which you may already be using: Annual performance bonuses reinforce recognition of individual performance while helping people focus on achieving individual performance goals and recognition.

- Group financial incentives reinforce social needs by rewarding team success and thereby focusing employees on working in a group to achieve common goals.

- Individual tips can encourage high customer service, while pooled tips can encourage servers to work together.

- Ownership in the company (through stock) helps employees realize how their personal success depends on the company's overall success. This can satisfy social needs (i.e., when the company succeeds, our social group succeeds) and achievement needs (i.e., when the company achieves, I also feel a sense of achievement).

Depending on how a financial reward is presented, it can help satisfy recognition needs as well as financial needs. So different pay methods can focus your employees on achieving high performance. As a caution, though, just as the manager's reinforcement changed the job of the buffet greeter, financial incentives can change behaviors, and so you should be sure that the behaviors you are rewarding are the ones you truly want to see in your employees.

Financial rewards can be a powerful motivator that can reinforce your efforts to build a culture of service excellence. Your employee motivation program can be strengthened even further with nonfinancial rewards, as we explain next.

\section{Nonfinancial Rewards}

Many of the reasons why people behave as they do have nothing to do with money (e.g., bringing up children, helping a stranger, volunteering in the community, caring for parents). Consequently, nonfinancial rewards like recognition, praise, personal growth, and an enjoyable working environment (which cost you little or nothing) can produce results that money could never buy. Let's look at the most common nonfinancial rewards. 


\section{Recognition Programs}

The purpose of a recognition program is to say "thank you" or "well done." Nearly 90 percent of companies offer some form of recognition program. You can recognize your employees for length of service, exceptional performance, sales performance, innovative suggestions, safety, or attendance, as well as celebrating their retirement. The rewards that go along with these recognitions include plaques or certificates, company logo merchandise, gift certificates, jewelry, office accessories, household items, recreational items, and electronics - and even a night or two as a guest of your hotel. ${ }^{5}$ These awards are designed to reinforce employee behaviors that support and sustain the company's mission. Awards like these can clearly demonstrate that you desire and appreciate your employees and their work efforts.

A key advantage of these recognitions is that they can create a lasting memorable experience. Not only does the employee have the award itself, but that person has feelings of pride from receiving a plaque, lasting feelings of appreciation or success by having a trophy, or fond memories stirred by photos from a special vacation. Often, the emotional connection of a physical recognition is much stronger than what you'd get from receiving an equivalent amount of money. For example, a trophy that announces an employee's outstanding service may cost only $\$ 20$, but the emotional impact of receiving a trophy is far greater than that of simply receiving a $\$ 20$ bill. The trophy presentation can be something that the employee never forgets.

Fairmont Hotels developed a recognition program designed to reinforce their service culture. The program features different award levels, such as "Memory Maker" for an outstanding demonstration of thoughtfulness and creativity, and "Star of the Month" for those who consistently demonstrate superior performance. ${ }^{6}$ Employees at all levels are nominated by peers. Thus, the program helps support Fairmont's culture of appreciation and recognition for everyone. Award winners receive gift certificates in small denominations (typically $\$ 10$ to $\$ 50$ ) that can be redeemed with thousands of merchants from around the world. Surveys of Fairmont's employees after the program was implemented revealed that employees felt more recognized for a job well done, felt the best performers were more likely to receive recognition, and felt that they were being recognized in a way that was personally meaningful. Surveys also showed that employees' level of engagement increased significantly since the program's inception.

\section{Making the Job Pleasurable}

Sometimes the work itself can be its own reward. Walt Disney said, "You don't work for a dollar-you work to create and have fun." ${ }^{7}$ Chili's Norman Brinker said, "If you have fun at what you do, 
you'll never work a day in your life. Make work like play-and play like hell." ${ }^{8}$ Employees who like what they do continue to do it. Not surprisingly, the reverse is also true; dozens of research papers have shown that low employee satisfaction is a strong predictor of employee turnover. ${ }^{9}$ The best hotel companies regularly survey their employees to assess their job satisfaction and other attitudes, such as employee relationships with their bosses, their feelings about their pay, and opinions about working conditions. ${ }^{10}$ You might consider asking your employees what part of their job holds them back from doing their best, so that you can reconfigure their jobs to focus on the parts that they like best-and therefore perform best. What one employee dislikes, another may find just ideal.

\section{Making the Job Interesting}

Obviously, you want to hire people who already want to do the job you hired them to do and are able to perform their job responsibilities. You can make sure of this through an effective recruitment and selection process. But once you have hired qualified people, you want to make sure they remain interested in performing the specifics of their job at the level you need them to. You can make most jobs interesting by using one or more of the following four elements:

1. Give employees the ongoing opportunity to learn and grow, both personally and professionally. People often want to feel a growing sense of professional mastery in their area of interest, but jobs with little to no variation can lead to burnout. Employees may have the ability to perform well, but may have done the same routine task so many times that they simply don't feel like doing the job as well as they can. Job rotation may be effective for some employees in this case, but others want to continue to perform jobs for which they comfortably feel they are qualified. So you might also consider ways to develop new interactions, new tasks, and new challenges.

2. Workers expect to be treated with respect. As employees learn and grow, you may show this by increasing employees' personal responsibility. Increased autonomy can be a sign of organizational respect for their knowledge, skill, and capabilities. In more dayto-day ways, employees need to be treated with integrity (as discussed in Chapter 31). If workers are not treated with respect, the only factor keeping them connected to the company will be their paychecks. If that is the case, once another company provides an equal or better offer, those employees (and all that you invested in them) may walk out your door. 
3. Make each job important by making clear its purpose in the organization. If employees think that their job performance really makes a difference in the organization's ability to provide an excellent experience to the customer, then they will feel good about performing their roles well. They will have pride in their job and their organization. Finding ways to show employees that what they do makes a difference to an important operation is a key motivational skill of managers of successful hospitality firms.

4. Arrange to satisfy individuals' social needs as part of the job. Many people want to be part of a good work group, or more generally have relationships with other people where they work. This is particularly true in the hospitality industry. Well-designed work groups can be helpful in managing employee direction and behavior in the workplace. Indeed, as studies at the Hawthorne Plant of the Western Electric Company showed many years ago, the sense of belonging or not belonging greatly influences what people will or won't do in the workplace. ${ }^{11}$ The managerial focus here should be to work in harmony with the group to support each employee's effort to achieve the group goal, which will help achieve your hotel's goal.

Groups may also offer members the opportunity to achieve something greater than themselves by being a part of the group. Membership in organizations with strong corporate cultures and whose purposes are respected by the society as a whole is valuable to both groups and individuals. Asking a group to help accomplish the valued, respected organizational purpose becomes a powerful motivational tool and a primary means for keeping the individual and the group positively involved in your operation.

\section{Motivation and Corporate Social Responsibility}

\section{JoAnne Kruse, Founder@www.HC-partners.net}

In these challenging economic times, most human resources (HR) organizations are struggling with shrinking budget allocations for services that were historically considered standard, like training, recognition, and incentives. But even in a labor market flush with available talent, the concepts of retention and engagement are of critical importance. At this writing, the unemployment rate hovers around 10 percent in the United States, but how does an employer keep those employees still on-board engaged and motivated to perform without access to the traditional motivators of compensation and career mobility? Adding even more 
to complicate the equation is the social tone that resists any level of conspicuous consumption. This results in a workplace environment that encourages a low-cost approach to motivation. Together, these dynamics create an ongoing pressure for employers to deliver on true productivity gains while retaining talent when the market does (eventually) pick back up.

Even before the Great Recession, sectors like travel and hospitality were dealing with significant volume declines. Barely able to recover from the impact of $9 / 11$, the travel sector then faced one global crisis after another, including the 2004 tsunami, terrorist bombings in Bali and London, and Severe Acute Respiratory Syndrome (SARS). As the chief HR executive in the travel sector with Travelport Ltd., a travel technology company, I saw the industry enter the millennium dealing with rapid erosion of the top line and a heightened focus on cost containment. At the same time, the employment market was strong, making retention and talent acquisition challenging. Part of our strategy included developing a corporate social responsibility (CSR) strategy to differentiate ourselves with customers and employees. We believed that employee productivity could be improved through higher levels of employee engagement. Applying Corporate Leadership Council research on engagement, we developed a broad array of programs to build employee engagement to drive effort and results. Our CSR initiative was one such program, combining our internal focus on engagement with good business and customer initiatives.

The tragic, deadly Indian Ocean tsunami of 2004 acted as a call to action for Travelport management, and the impetus to develop a broader CSR program that included "voluntourism," charitable giving, and environmentalism. The program had three core goals: engage employees around the world in local volunteer and giving programs; create and deliver against a green strategy for our hundreds of facilities located globally; and align our program investments with our business development and customer interests. The horrific destruction of the tsunami in Thailand provided a critical need, and our initial investment centered on a fund-raising effort to rebuild a destroyed orphanage in the resort area of Phuket. We designed the program with a global logo, Web-based donation site, and ongoing postings of pictures and fund-raising results on the company intranet. The program was successful, raising over $\$ 250,000$ in a little over three months - with all regions participating, including those where charitable efforts are less culturally common than in the U.S. Employees rallied around the company and the commitment demonstrated to "doing the right thing," providing a bonding moment for local teams and a recommitment to the executive team's leadership. In the midst 
of significant uncertainty and marketplace challenges, employee satisfaction soared, and feedback from the event continued for years following. The broader CSR program then followed suit, with a commitment to "design globally, apply locally," further reinforcing the company's organizational structure and approach to product and service delivery. Further, the opportunity to deliver a positive message to customers proved a much-needed boost for our sales and service teams.

The CSR program became a living example of how the Travelport culture and values were demonstrated-to our employees and customers-around the world. By "walking the talk" we were able to reengage a change-weary employee base and motivate employees and customers around the world by delivering a sense of pride in the company.

\section{The Motivating Characteristics of the Job}

Finally, let's look at the interaction of the employee with the job itself Many people are powerfully motivated intrinsically, or internally. Unattached to specific rewards of any kind, intrinsic motivation is caused by the nature of the person and their environment. One way to take advantage of this is to hire people motivated to perform exceptional service. Another way to foster intrinsic motivation is by structuring the job and work environment to build on employees' personal motivation. Leadership

It is impossible to overstate the importance of your role as a leader. Leaders must also be able to identify and provide those rewards that the individual employee wants from working in your hotel or restaurant. Effective leadership involves inspiration, challenge, and a strategic vision. Creating a shared

purpose among employees can effectively foster motivation. ${ }^{12} \mathrm{~A}$ great leader creates the conditions that promote employee engagement.

\section{Charles A. Conine, SPHR, Cornell 1973}

Detroit, Michigan, 1977. The morning sun was reflected in prisms of light off the newly opened, 73-story Detroit Plaza Hotel at the Renaissance Center, the glass centerpiece of and home to what was billed as the Motor City's resurgence. Nearly 2,500 Detroiters had been hired to staff this new Westin hotel. Many, due to Detroit's riots, chronic unemployment, and systemic poverty, had never worked a day in their adult lives before being put on the payroll at 
the "Ren Cen." My task preopening had been to shepherd 12,000 job applicants, sifting through their midst to identify those whose attitude was at least good- not an easy job in a bruised and battered city where "hope" was far from the most common of four-letter words.

Now, with the hotel finally open, as director of personnel, I watched as right away, immovable and opposing forces assembled. On one side were 2,250 union members led by a feisty union business representative. On the other side was Westin's large and as yet unproven management team. "Battles royal" raged for several months, with employees, sometimes at the union's behest, often camping outside my door three deep, hankering to get a crack at convincing me why their boss was guilty of racism and why the employees shouldn't be picked on. Management felt rather picked on, too. I felt engulfed, without a way out.

Finally, in desperation I met with the union business rep, who, to her everlasting credit, suggested we create a shop steward's council, a place for the hotel's departmental union representatives to go and air issues without fear of retribution. We soon found ourselves there, the opposing forces eyeing one another warily before the floodgates opened and out poured dozens of complaints, simmering issues, and stories of mistreatment.

Over the course of three successive steward meetings, however, as issues were heard and, in most cases, quickly addressed, the number and ferocity of complaints gradually subsided. We had turned a corner, discovering what really worked: the knowledge that when management and subordinates care equally about respect and working conditions, mutual animus recedes as mutual trust ascends.

Knowing that your concerns will be heard and taken seriously can be a powerful motivator. Indeed, as the nascent truce took hold, its calm spreading as everyone's motivation to work together improved, the "climate" inside the hotel, in that crucible I'll forever recall as simply "the Spring of 1977," became downright balmy.

\section{Empowering Employees}

Most hospitality operations function with employee teams, which need to grow and develop just as individuals do. One great asset that a team provides to its members is the opportunity to grow within the group setting. But the organization must provide additional opportunities for its members to satisfy this important need. The most widely discussed strategy for doing so is empowerment.

Empowerment is the assignment of appropriate decision-making responsibility to the

individual. ${ }^{13}$ Empowerment is broader than the traditional concepts of delegation, decentralization, and 
participatory management. Empowerment stretches decision responsibility to include the entire job and ensures that the performance of that job fits with the organizational mission. The empowered server can personalize the service experience as it relates to each guest's expectations and can take whatever steps are necessary to prevent or recover from any service failures.

The danger in empowerment is that some organizations promise employees decision input without giving them any real power or authority. Employee empowerment must not only ensure that effective decisions are made by the right employees, but it must provide a mechanism by which responsibility for job-related decisions is vested in either individuals or teams. ${ }^{14}$ Empowerment also means that management is willing to share relevant information about and control over factors that impinge on effective job performance. You are not obliged to ratify every employee decision. If the employees make a decision contrary to your hotel's policies, further discussion is required, but you cannot second-guess every employee decision.

Hyatt Hotels, for example, felt that they should provide better hospitality to their most loyal customers. So Hyatt began a program that empowered employees to perform what they called "random acts of generosity." One member in the loyalty program might suddenly find that his bar tab was paid, another may receive a complimentary massage, or a member and her family may discover that the hotel has paid for their breakfast. As you can imagine, there's no way to dictate a set of policies that would tell employees how to surprise and delight guests. Instead, Hyatt empowered their employees to see a situation and make the right decision to provide exceptional customer experiences. The intent of the empowerment is to help fulfill the company's mission, which they define as making a difference in the lives of the people they touch-including guests and employees.

\section{Putting the Pieces Together}

Motivation is so complex that no single policy will help you motivate your employees. While you cannot ignore the reality that financial rewards play a critical role in motivating hospitality employees, you cannot also ignore the reality that money isn't everything to everyone. Recognition and feedback can also be effective tools, if you have the leadership and management skills to know when and how to provide these nonfinancial rewards effectively. The work itself can be highly motivating if designed appropriately. Yet a job cannot be designed without considering your hotel's culture, the training employees receive, the types of employees selected, and the way the service product is delivered. Putting all the pieces together in ways that lead every employee to do what they must do for organizational success is the true test of a manager's skill. 
For the most part, hospitality employees look for jobs that are fair, fun, interesting, and important. They appreciate leadership by managers who can determine what each person is looking for in the employment relationship and can provide it consistently and fairly. Given what we know about motivation in the hospitality industry, the key to managing and retaining these employees is to create jobs that fulfill your employees' quest for fun, fair, interesting, and important positions; allocate rewards fairly; and provide leadership that takes the time and makes the effort to ensure that employees are appropriately treated, rewarded, respected, and recognized. If you can successfully build these elements into the job situation, employees will be motivated to work hard and follow your leadership. The trick is that everyone's definition of fair, fun, interesting, important, and appropriately managed is different. Thus, we must conclude by saying that the fundamental key to motivation is to know your employees.

\footnotetext{
${ }^{1}$ For example, see www.snopes.com/business/consumer/badhotel.asp.

${ }^{2}$ A. H. Maslow, "A Theory of Human Motivation," Psychological Review 50(4) (1943): 370-396.

${ }^{3}$ G. P. Latham, Work Motivation: History, Theory, and Practice (Thousand Oaks, CA: Sage, 2007).

${ }^{4}$ C. Albrecht, "Sales Compensation and the Fairness Question," Workspan 8(9) (2009): 17-20.

${ }^{5}$ World at Work, A Survey of Members of WorldatWork and the National Association of Employee Recognition (NAER), May 2005.

${ }^{6}$ M. Smith and D. Irvine, "The Power of Fairmont Hotels and Resorts' Strategic Employee Recognition Program," Workspan 52(8) (2009): 28-32.

${ }^{7}$ W. Disney, Famous Quotes (Anaheim, CA: Walt Disney Theme Parks and Resorts, 1994), 36.

${ }^{8}$ N. Brinker and D. T. Phillips, On the Brink: The Life and Leadership of Norman Blinker (Arlington, TX: Summit, 1996), 191.

${ }^{9}$ N. P. Podsakoff, J. A. LePine, and M. A. LePine, "Differential Challenge Stressor-Hindrance Stressor Relationships with Job Attitudes, Turnover Intentions, Turnover, and Withdrawal Behavior: A Meta-analysis," Journal of Applied Psychology 92 (2007): 438-454.

10 J. Barsky, C. Frame, and J. McDougal, "Variety of Strategies Help Improve Employee Satisfaction," Hotel and Motel Management 219(21) (2004): 8.

${ }^{11}$ E. Mayo, Hawthorne and the Western Electric Company: The Social Problems of an Industrial Civilisation (Oxford, UK: Routledge, 1949).

12 J. C. Tinimerman, "A Systematic Approach for Making Innovation a Core Competency," Journal of Quality and Participation 31(4) (2009): $4-10$.

${ }^{13}$ Based on R. C. Ford and M. D. Fottler, "Empowerment: A Matter of Degree," Academy of Management Executive 9(3) (1995): 21-28.

${ }^{14}$ L. C. Plunkett and R. Fournier, Participative Management: Implementing Empowerment (New York: Wiley, 1991), 5.
} 